\title{
Early Invasion of Common Cordgrass (Spartina Anglica) Increases Belowground Biomass and Decreases Macrofaunal Density and Diversity in a Tidal Flat Marsh
}

\author{
Wonhyeop Shin ( $\nabla$ dnsuql@naver.com ) \\ Seoul National University https://orcid.org/0000-0002-9798-5883 \\ Minwoo Oh \\ Seoul National University College of Natural Sciences \\ Jae-Sang Hong \\ Inha University College of Natural Sciences \\ Chaeho Byun \\ Andong National University \\ Eun Ju Lee \\ Seoul National University College of Natural Sciences
}

\section{Research Article}

Keywords: Tidal flat marsh, Patch size, Biomass allocation, Species diversity, Spartina, Macrobenthos communities

Posted Date: July 30th, 2021

DOI: https://doi.org/10.21203/rs.3.rs-600630/v1

License: (c) (i) This work is licensed under a Creative Commons Attribution 4.0 International License.

Read Full License 


\section{Abstract}

Spartina anglica is an invasive perennial marsh grass causing significant negative impacts on tidal flat ecosystem. There have been only a few studies focusing on the patch structure of $S$. anglica according to size and its effects on macrofauna. A field experiment was conducted to identify effects of $S$. anglica patches where they have been introduced no later than 5 years after invasion occurred on macrofauna assemblages. The survey area was divided into two sections according to vegetation: (1) Suaeda japonica vegetation from 0 to $60 \mathrm{~m}$ away from the embankment, and (2) bare mudflat from 60 to $90 \mathrm{~m}$ away from the embankment. The patch sizes of $S$. anglica were categorized into small $\left(1-4 \mathrm{~m}^{2}\right)$, medium $\left(5-11 \mathrm{~m}^{2}\right)$, and large (13-40 $\left.\mathrm{m}^{2}\right)$ in area with four replicates for each section. The biomass ratio of the belowground and aboveground in the small size patch of $S$. anglica was significantly higher than those in the medium and large size patch of $S$. anglica. It indicated that more resource was allocated to rhizomes in small size patch with short invasion history (1 2 years). After $S$. anglica invaded, macrofauna richness (70\%), Shannon-Wiener diversity (80\%), and density (67\%) were decreased. However, infaunal deposit-feeding polychaete Perinereis linea and epifaunal gastropods Batillaria cumingi and Lactiforis takii increased by $S$. anglica. Ordination of macroinvertebrate assemblages separated the habitat with $S$. anglica invasion from the adjacent uninvaded tidal flat and Suaeda japonica habitats. This study offers a significant insight into early invasion strategies of an aggressive plant invader, $S$. anglica for management of coastal wetlands and its impacts on macrofaunal assemblages.

\section{Introduction}

Tidal flats and salt marshes provide diverse ecosystem services, as well as food and habitat to numerous animal fauna such as benthic macrofauna, birds, and fish (Costanza et al. 1997; Barbier et al. 2011). Mudflats form an integral part of estuarine coastlines and play an important role in flood defense (Möller et al. 2014). Mudflats also act as an essential sediment source for adjacent salt marshes (Temmerman et al. 2004; Ganju et al. 2015). However, ecosystem destruction and alien species invasion are increasing due to anthropogenic disturbance and global climate change (Worm et al. 2006; Ayres 2002). Wetlands and coastal habitats are particularly vulnerable to invasive species due to the influence of tidal dynamics and frequent disturbances (Lodge and David 1993; Boorman 1999; Schirmel et al. 2016).

The grass Spartina anglica CE Hubbard (Poaceae) was first discovered on Ganghwa Island in Incheon, South Korea in 2008 (Raybould et al. 1991; Hedge et al. 2003; Kim et al. 2019); it was designated as one of the world's worst invasive alien species by the International Union for Conservation of Nature (IUCN) in 2000, and as a harmful marine organism by the South Korean Ministry of Ocean and Fisheries in 2016. Spartina anglica is thought to have evolved following hybridization between Spartina alterniflora Louiseleur in the northeastern United States with Spartina maritima Fernald, a native species of the southern coast of England (Raybould et al. 1991; Baumel et al. 2002). Various Spartina species have been deliberately introduced in estuarine and coastal habitats of Britain (Gray et al., 1991), North America (Ayres and Strong 2002), China (Chung 1993; Zuo et al. 2012), Japan (Kimura et al., 2016), New 
Zealand (Hubbard and Partridge 1981), and Australia (Kriwoken and Hedge 2000) to stabilize tidal flats, embankments, and coastlines, because its roots and rhizomes intertwine with plants.

The development and propagation of $S$. anglica strains is still ongoing, destroying existing native vegetation and changing ecological environments worldwide (Cutajar et al. 2012; Daehler et al. 1996; Xiao et al. 2010). Spartina anglica transforms marine habitats into monocultures (Hacker et al. 2001), changes sediment characteristics such as grain size, $\mathrm{pH}$, salinity, and organic matter content (Hubbard and Stebbings 1968; Netto and Lana 1997; Sheehan and Ellison 2014), and retards the flow of water through stiff aboveground shoots (Morris et al. 2002; Bouma et al. 2010). Several studies have examined the influence of $S$. anglica on macrofauna; it has been reported to block energy supply to tidal flat macroalgae as its shoots reduce light transmittance, thereby significantly altering macrobenthic communities and the food web (Netto and Lana 1997, Thompson 1991; Levin et al., 2006; Neira et al. 2006; Cottet et al. 2007; Wang et al. 2010; Cutajar et al. 2012). As S. anglica patches expand, algae are transformed into detritus and subsurface deposit feeders increase in abundance, while suspension feeders and detritivores decrease (Cutajar et al. 2012; Neira et al. 2006). Quantifying the impacts of plant invasion on benthic communities is important for understanding the underlying causes of invasion (Snelgrove 1998; Prieur-Richard et al. 2000; Wu et al. 2009). Spartina invasion was accompanied by decreased species diversity $\left(\mathrm{H}^{\prime}\right)$ and abundance of infauna inhabiting the seafloor (Neira et al. 2007; Tang and Kristensen 2010, Cutajar et al. 2012), and a substantial reduction in macrofauna species richness and diversity in northern Europe and Australia (Chen et al. 2007; Neira et al. 2007; Tang and Kristensen 2010), but had no impact on benthic invertebrates or fish in Tasmania, southeastern Australia (Hedge and Kriwoken 2000; Wu et al. 2009). Salt marsh restoration using S. maritima has been reported to increase the complexity (ecological diversity and species richness) and abundance of some benthic macroinvertebrate communities (Curado et al., 2014).

However, few studies have examined the effect of $S$. anglica patch size and structure on benthic macrofauna. In this study, we investigated the patch structure of early invasion $S$. anglica (< 8 years of invasion history), and the impact on macrofauna communities in various habitat types. The objective of this study was to identify the structural characteristics of $S$. anglica in the early stage of invasion, to characterize its energy allocation pattern and determine the dispersal strategies of independent patches. We also conducted cluster analysis to evaluate the effects of $S$. anglica on macrobenthic distribution.

\section{Materials And Methods}

\section{Study area}

This study was conducted in a tidal marsh in May 2016 in southern Dongmak-ri, Ganghwa Island, South Korea $\left(37^{\circ} 35^{\prime} 36.97^{\prime \prime} \mathrm{N}, 126^{\circ} 26^{\prime} 32.36^{\prime \prime} \mathrm{E}\right)$ (Fig. 1). In 2017 , the study area had a mean annual temperature of $11.74^{\circ} \mathrm{C}$ (maximum, $6.88^{\circ} \mathrm{C}$; minimum, $16.84^{\circ} \mathrm{C}$ ), total annual precipitation of $787 \mathrm{~mm}$, mean wind velocity of $2.02 \mathrm{~m} / \mathrm{s}$, and total annual sunshine duration of 2,274.2 h (Ganghwa weather station, Korea Meteorological Administration). The three most common native marsh plant species at the study sites 
were Suaeda japonica Makino, Triglochin maritimum Linne, and Phragmites communis Trinius. Suaeda japonica vegetation was under colonization by Spartina anglica in both dense monotypic patches and meadows.

\section{Vegetation survey}

To investigate variation in S. anglica patch structure, we surveyed 24 Spartina patches near the embankment (Fig. 2). To examine each patch independently, we included only those at distances of $>2 \mathrm{~m}$ from all other patches. Neira et al. (2007) reported that changes in Sparti na growth stages and macrofaunal communities were related to sediment and environmental properties. Suaeda japonica vegetation was observed at 0-60 m from the embankment, and on bare mudflats without other vegetation at $60 \mathrm{~m}$ from the embankment. Through stratified random sampling, we divided $S$. anglica patches into small $\left(1-4 \mathrm{~m}^{2}\right)$, medium $\left(5-11 \mathrm{~m}^{2}\right)$, and large $\left(13-40 \mathrm{~m}^{2}\right)$ size classes, with four replicates per habitat. We used a drone (Mavic Pro; DJI Co., China) to obtain photographs of the study site, which were converted into shapefiles using eCognition 64 software (Trimble, USA). Patch sizes were calculated using ArcGIS 10.1 software (Esri, USA).

In the field survey, we measured the circumference, and minimum and maximum diameter, of each $S$. anglica patch for comparison with the estimated patch sizes. Aboveground $S$. anglica shoots were harvested by clipping the vegetation at the sediment surface in quadrats $(1 \mathrm{~m} \times 1 \mathrm{~m})$. The height and density of five living and five dead shoots, selected from the four edges and center of each quadrat, were measured. Dead shoots and leaves were identified by their yellow or brown color (Darby and Turner 2008). All aboveground materials were stored in plastic bags in a refrigerator at $4^{\circ} \mathrm{C}$. Each individual was divided into stems and leaves, and then washed with water about 10 times to remove sediment. Living or dead plant material was placed in paper bags, dried at $80^{\circ} \mathrm{C}$ for approximately $72 \mathrm{~h}$, and then weighed to the nearest $0.01 \mathrm{~g}$. Aboveground Suaeda japonica biomass was harvested and weighed following the same procedures. Belowground S. anglica biomass (rhizomes and roots) was collected using a $10-\mathrm{cm}-$ long polyvinyl chloride (PVC) core (diameter, $15 \mathrm{~cm}$ ). Two replicates of each soil core were collected in each quadrat. The samples were stored in plastic bags in a refrigerator at $4^{\circ} \mathrm{C}$. The segments were washed in a $500-\mu \mathrm{m}$ sieve to prevent loss of fine root materials. Belowground materials were separated into roots and rhizomes, which were placed in separate paper bags, dried at $80^{\circ} \mathrm{C}$ for approximately $72 \mathrm{~h}$, and weighed to the nearest $0.01 \mathrm{~g}$.

We collected 15-cm-diameter sediment cores to a depth of $10 \mathrm{~cm}$ for macrobenthic faunal analysis, with two replicates. In the laboratory, the cores were washed through 500- $\mu \mathrm{m}$ mesh. Animals retained on the sieve were preserved in $70 \%$ ethanol, sorted, counted and weighed to the nearest $0.001 \mathrm{~g}$, and identified to the lowest possible taxonomic level using a dissecting or compound microscope. As a control group, we randomly selected and sampled bare mudflats and patches of Suaeda vegetation $1 \mathrm{~m}$ from the Spartina patches; sampling followed the procedures described for $S$. anglica. 


\section{Bottom sediment analysis}

To analyze sediment characteristics, we collected sediment samples at a depth of $5 \mathrm{~cm}$ and isolated 300 $\mathrm{g}$ of sediment from each sample. We dried $5 \mathrm{~g}$ of each isolated sediment at $105^{\circ} \mathrm{C}$ for $24 \mathrm{~h}$ to determine its water and ash content, and at $550^{\circ} \mathrm{C}$ for $4 \mathrm{~h}$ to determine its organic content. We mixed $7 \mathrm{~g}$ of air-dried soil with $35 \mathrm{~mL}$ distilled water to obtain a suspension, which was subjected to shaking at $180 \mathrm{rpm}$ for 30 min and centrifugation at 3,000 rpm for $1 \mathrm{~min}$. We measured salinity and pH using a PC-2700 system (Thermo Eutech, Singapore) fitted with the CONSEN9201J and ECFG7370101B probes, respectively. $\mathrm{NH}_{4^{-}}$ $\mathrm{N}$ in sediment was extracted with a $2 \mathrm{M} \mathrm{KCl}$ solution, and $\mathrm{PO}_{4}-\mathrm{P}$ was extracted with Bray No. 1 solution (Bray and Kurtz 1945). $\mathrm{NH}_{4}-\mathrm{N}$ and $\mathrm{PO}_{4}-\mathrm{P}$ in the extracted soil solutions were analyzed using the indophenol (Murphy and Riley 1962) and ascorbic acid reduction (Solorzano 1969) methods, respectively

\section{Statistical analyses}

Several assemblage indices were calculated to compare benthic macrofaunal assemblages, including species richness, density, Shannon-Wiener H', and biomass (Pielou 1966). Differences in assemblage indices, environmental variables, and $S$. anglica patch structures among habitats were tested by one-or two-way analysis of variance (ANOVA) and Tukey's honestly significant difference (HSD) test using $R$ v3.3.2 software (R Development Core Team, Austria). Canonical correspondence analysis (CCA) was performed to examine the relationships between macrofaunal assemblage and environmental variables.

\section{Results}

\section{Spartina anglica density, height, coverage, and biomass}

Characteristics of $S$. anglica according to patch size and habitat were investigated to understand its growth strategy. Living and dead shoot density ranged from $173.5-227$ and $163.25-225.75 \mathrm{~m}^{-2}$, respectively. Living and dead shoot height ranged from $33.55-40.10$ and $83.45-128.7 \mathrm{~cm} \mathrm{~m}^{-2}$, respectively. Living organ coverage ranged from $36.25-65 \% \mathrm{~m}^{-2}$ (Appendix 1). No discernable patterns were observed among patch sizes and habitats in terms of average living or dead shoot density $(P>0.05)$ (Appendix 2). Living $S$. anglica shoot height was significantly higher among Suaeda japonica vegetation than in the adjacent bare mudflats $(P<0.05)$ (Fig. 3). Dead shoot height was significantly higher among large than small $S$. anglica patches $(P<0.05)$ (Fig. 3). Living $S$. anglica coverage differed significantly by S. anglica patch size $(P<0.001)$, and between Suaeda habitat and bare mudflats $(P<0.05)($ Fig. 3$)$.

Living aboveground and belowground $S$. anglica biomass ranged from 42.91-57.21 and 176.89-302.22 $\mathrm{g} \mathrm{m}-2$, respectively. Aboveground biomass corresponded to $16-23 \%$ of the belowground biomass. Living leaf biomass and rhizome biomass differed significantly by patch size and habitat type (Fig. 3). Rhizome biomass was significantly higher in small than medium and large $S$. anglica patches $(P<0.001)$. Dead 
leaf biomass was significantly higher among Suaeda japonica vegetation than on the bare mudflats. The ratio of below- to above-ground biomass was significantly higher in small S. anglica patches (Fig. 4).

\section{Macrobenthic community survey}

In the present study, we identified a total of 16 benthic macrofauna from four habitats: bare mudflats, Spartina-invaded bare mudflat, Suaeda vegetation, and Spartina-invaded Suaeda vegetation. The highest macrobenthic species richness appeared in Suaeda vegetation (10 species; Table 1). However, bare mudflats had the highest total macroinvertebrate density, with 119 individuals $\mathrm{m}^{-2}$, consisting predominantly of the capitellid deposit feeder Mediomastus californiensis. Bare mudflats and Spartinainvaded Suaeda vegetation yielded fewer species (four and five, respectively), and were dominated by the nereidid deposit feeder Perinereis linea. Lower Annelida and Mollusca species richness and density were observed in Spartinainvaded habitats. Among polychaete annelid populations, Mediomastus californiensis showed the greatest reduction under Spartina invasion. Among molluscan populations, the laternulid bivalve Laternula gracilis showed the greatest decrease. Nine species found in habitats with no Spartina invasion were absent from Spartina-invaded habitats, whereas the epifaunal gastropods Batillaria cumingi and Lactiforis takii were found in Spartina patches.

Macrobenthic species richness was 70\% lower in Spartina-invaded bare mudflats than in bare mudflats without Spartina invasion; Spartina patches reduced the species richness of polychaete annelids to a greater extent than that of mollusks (Fig. 5). The mean H' was $>80 \%$ lower in Spartina patches than bare mudflats without invasion. The mean $\mathrm{H}^{\prime}$ was $94 \%$ lower in Spartina patches than Suaeda vegetation without Spartina invasion. Spartina patches reduced the diversity of annelids to a greater extent than molluscs (Table 1). Overall, mean species richness and density were significantly lower in Spartina patches, whereas no significant difference was detected between bare mudflats and Suaeda vegetation without Spartina invasion (Fig. 5).

CCA ordination results were based on macrobenthic density data and six environmental variables: organic matter, $\mathrm{NH}_{4}-\mathrm{N}$, and $\mathrm{PO}_{4}-\mathrm{P}$ content, $\mathrm{pH}$, salinity, and belowground biomass (Fig. 6). The variance explained by the first two CCA axes was $51.34 \%$ and $26.81 \%$, respectively ( $78.15 \%$ in total; Table 2$)$. The first axis was significantly related to $\mathrm{pH}$ (factor loading $=0.6387$ ) and belowground biomass (factor loading $=-0.9453)($ Table 2$)$, whereas the second axis was significantly related to $\mathrm{NH}_{4}-\mathrm{N}$ content (Table 2). From right to left on the first CCA axis, the macrofaunal assemblages showed zonation from bare mudflats and Suaeda japonica vegetation to $S$. anglica-invaded mudflats and $S$. anglica-invaded Suaeda japonica vegetation (Fig. 6). In both mudflats and Suaeda japonica vegetation areas, zones with and without $S$. anglica invasion were clearly distinguished (Fig. 6), with S. anglica invasion zones showing higher organic matter content, salinity, and belowground biomass, and lower $\mathrm{pH}$, than zones without invasion.

Table 1 
Species density and richness $\left(/ \mathrm{m}^{2}\right)$ in bare mudflat and Suaeda japonica vegetation habitats (all samples combined). E, epifauna; I, infauna.

Bare mudflats

No

invasion
Suaeda vegetation

No Spartina invasion

Annelida

\begin{tabular}{|c|c|c|c|c|}
\hline Eteone sp. (I) & 2.83 & 0 & 0 & 0 \\
\hline Glycera macintoshi (I) & 0 & 0 & 2.83 & 0 \\
\hline Glycinde gurjanovae (I) & 0 & 0 & 5.66 & 0 \\
\hline $\begin{array}{l}\text { Mediomastus } \\
\text { californiensis (I) }\end{array}$ & 152.79 & 0 & 107.52 & 8.49 \\
\hline Nephtys chemulpoensis (I) & 8.49 & 2.83 & 19.81 & 0 \\
\hline Oligochaeta sp. (I) & 11.32 & 0 & 2.83 & 0 \\
\hline Paraleonnates uschakovi (I) & 0 & 0 & 2.83 & 0 \\
\hline Perinereis linea (I) & 84.88 & 31.12 & 42.44 & 135.81 \\
\hline Total density & 260.31 & 33.95 & 183.91 & 144.3 \\
\hline Species richness & 5 & 2 & 7 & 2 \\
\hline \multicolumn{5}{|l|}{ Mollusca } \\
\hline Batillaria cumingi $(\mathrm{E})$ & 0 & 0 & 0 & 2.83 \\
\hline Estellacar galactodes (I) & 2.83 & 0 & 2.83 & 0 \\
\hline Glauconome chinensis (I) & 2.83 & 0 & 0 & 2.83 \\
\hline Lactiforis takii (E) & 0 & 8.49 & 2.83 & 0 \\
\hline Laternula marilina (I) & 67.91 & 0 & 45.27 & 5.66 \\
\hline Moerella rutila (I) & 2.83 & 0 & 0 & 0 \\
\hline Potamocorbula sp. (I) & 0 & 5.66 & 0 & 0 \\
\hline Total density & 76.39 & 14.15 & 50.93 & 11.32 \\
\hline Species richness & 4 & 2 & 3 & 3 \\
\hline
\end{tabular}

\section{Discussion}


Our results showed that the structural characteristics of invading Spartina patches, including living leaf biomass, rhizome biomass, and coverage, were dependent on Spartina patch size. Small patches had significantly higher rhizome biomass than medium-sized and large patches at depths of $0-10 \mathrm{~cm}$. Patch size is related to invasion history: smaller patches indicate a shorter invasion history. Therefore, we assume that changes to $S$. anglica structural characteristics occur after invasion and spread throughout the patches.

At the study area, Spartina anglica patches with a short invasion history allocated resources to roots and rhizomes, to settle early populations and adapt to harsh environmental stresses such as high salinity and tides. Schubauer and Hopkinson (1984) also reported that rhizomes accounted for a greater portion of belowground biomass in a Georgia salt marsh. Investment of resources into rhizomes is crucial for the invasion of clonal plants, such as $S$. anglica, allowing them to adapt to a wide range of habitats by maintaining soil volume (Petrone et al. 2001). If belowground organic matter accumulation is insufficient, marshes with abundant aboveground plants can rapidly become open water, as accumulated sulfide causes plant death. Clonal integration is an important means of population expansion for the invasive Phragmites australis, which would otherwise be confined to higher-elevation marshes due to low oxygen availability at lower elevations (Amsberry et al. 2000).

Table 2

Factor loadings of variables obtained by canonical correspondence analysis (CCA). Zonation was determined at standard error (SE) $>0.600$ (bold).

\begin{tabular}{lll} 
& CCA1 & CCA2 \\
\hline Organic matter & -0.4199 & 0.3435 \\
\hline $\mathrm{NH}_{4}-\mathrm{N}$ & 0.5127 & $\mathbf{0 . 6 5 5 7}$ \\
\hline $\mathrm{PO}_{4}-\mathrm{P}$ & 0.1575 & 0.3174 \\
\hline $\mathrm{pH}$ & $\mathbf{0 . 6 3 8 7}$ & -0.2434 \\
\hline Salinity & -0.3880 & 0.2218 \\
\hline Belowground biomass & $-\mathbf{0 . 9 4 5 3}$ & 0.1326 \\
\hline Proportion of variance & 0.5134 & 0.2681 \\
\hline Cumulative proportion & 0.5134 & 0.7815 \\
\hline Eigenvalues & 0.3819 & 0.1994
\end{tabular}

Aboveground and belowground biomass allocation are important for marsh ecosystem structure and function, because they influence various processes such as carbon sequestration, gas transport, nutrient cycling, and ecosystem resilience (Darby and Turner 2008; Tripathee and Schafer 2014; Castillo et al. 2016). The ratio of below- to above-ground biomass was significantly higher in small Spartina patches, 
suggesting differential carbohydrate use under harsh environmental condition (Castillo et al. 2016) despite its small range (0.13-0.16). In spring, high root and rhizome biomass can affect leaf biomass. Phragmites asturalis, Egertian densa, and Myriophyllum show depleted carbohydrate reserves in the rhizomes during rapid growth (Costa et al. 2003). Spartina alterniflora showed evidence of biomass translocation from below- to above-ground early in the growing season, when aboveground growth is at its maximum (Connor et al. 2000). However, the ratio of below- to above-ground biomass differed significantly according to settlement history and location within the marsh (Valiela et al. 1976; Roman and Daiber 1984; Wigand 2008). Dame and Kenney (1986) reported an average net aboveground primary production of 2,188 and $1,295 \mathrm{~g} \mathrm{~m}^{-2}$ year -1 at low and high elevations within the marsh, respectively, whereas the corresponding average net belowground primary production rates were 2,363 and $5,445 \mathrm{~g} \mathrm{~m}^{-}$

${ }^{2}$ year $^{-1}$. Ellison et al. (1986) also reported decreasing root and rhizome penetration $(<20 \mathrm{~cm})$ into the marsh substrate with increasing tidal height, and belowground biomass reached a maximum at the marsh edge.

In the present study, rhizomes sampled at depths of 6-9 $\mathrm{cm}$ were often curved, returning to the surface layer where they could become shoots. This finding indicates that depth should be considered as a major factor for the eradication of Spartina. Spartina densiflora is a halophyte with high salinity tolerance, but its growth is limited in halosaline conditions (Castillo et al. 2016). In the present study, salinity was not directly related to $S$. anglica biomass accumulation in any habitat; therefore, $S$. anglica may have greater salinity tolerance than $S$. densiflora.

\section{Effect of Spartina invasion on macrobenthic communities}

Intertidal macrobenthic communities usually vary by habitat type and tidal level (Hosack et al. 2006; Bouma et al. 2009; Compton et al. 2013). In the present study, the effects of Spartina on macrobenthic communities was estimated and compared to those in adjacent habitats. Plant introductions to salt marsh systems result in significant changes, ranging from species replacement to widescale alteration of ecosystem properties; these altered physical and chemical environments can also strongly influence the recruitment, survival, growth, and reproduction of benthic invertebrates in invaded areas. (Neira et al. 2005; Grosholz et al. 2009). Neira et al. (2005) observed 75\% lower total macrofaunal density, and lower species richness, in Spartina-vegetated sediments representing 30-year-old invasion at Elsie Roemer Bird Sanctuary (California, USA) than in an adjacent unvegetated tidal flat. Differences in macrofaunal community structure have been shown to be greater among tidal elevations than between native halophyte and invasive Spartina communities in Chinese estuarine Spartina-invaded tidal flats (Chen et al. 2009). The present study also revealed a significant association between Spartina invasion and macrofaunal assemblages. We observed macrofaunal changes in bare mudflats and Suaeda vegetation invaded by Spartina, including low species richness, $\mathrm{H}^{\prime}$, and macrofaunal density; more epifauna in Spartina-invaded bare mudflats; higher density of the subsurface deposit-feeding nereidid polychaete Perinereis linea in Spartina-invaded Suaeda vegetation; and no significant difference in macrobenthic biomass among habitats. Spartina invasion also affected macrobenthic communities depending on the 
invasion history, which was estimated to be 2-5 years at the study site. Even within such a short period, the impact of $S$. anglica on macrofaunal diversity and density was sufficiently strong to produce significant effects. To some extent, these results are consistent with previous findings obtained in a temperate Australian salt marsh (Cutajar et al. 2012), and in Wenzhou Bay, China (Get et al. 2012). Cutajar et al. (2012) reported that invaded patches showed a 50\% reduction in species richness, and reduced diversity, compared to two uninvaded habitats. Macrofaunal density in the $S$. anglica patches of the present study was also lower than that in native marsh (by 60\%), but not significantly different from that in the bare mudflats. We observed no differences in biomass among habitats. Ge et al. (2012) demonstrated that macrobenthic communities were more complex in initial $S$. alterniflora invasion patches than in patches at other invasion stages, and that $S$. alterniflora invasion stage significantly affected macrobenthic community structure; their results also indicated higher biodiversity in the initial stage of invasion (1-2 years), decreasing during invasion progress (3-4 years) until completion (5-6 years), perhaps due to $S$. alterniflora canopy changes.

Our CCA results indicated that the key environmental factors driving macrobenthic ommunity changes were belowground biomass, organic matter content, salinity, and pH (Fig. 6). S. anglica invasion was associated with low $\mathrm{pH}$, high organic matter content, high belowground biomass, and high salinity. These results are consistent with those of previous studies reporting changes in the physicochemical properties of sediment habitats under Spartina invasion (Neira et al. 2007). The macrofaunal diversity and density of tidal flat environments increase significantly when ecosystem engineers, such as oyster reef or seagrasses, are present because they create and modify habitat structures (Brusati and Grosholz 2006). In this study, comparison of macrofauna assemblages between habitats with and without Spartina patches showed clear trends (Fig. 6). Macrofaunal H' was higher in bare mudflats and native marsh than in habitats containing Spartina patches. Spartina patches yielded low macrofaunal diversity, low and richness in mudflats (Hedge and Kriwoken 2000). However, the infaunal polychaete $P$. linea, and the epifaunal gastropods B. cumingi and L. takii, were enhanced in Spartina patches. These findings are similar to previous reports of increased macrofaunal dominance with a shift in feeding mode from surface microalgal feeding to subsurface detritus feeding (Neira et al. 2007; Bouma et al. 2010), which creates Spartina-free areas in open mudflats (Brusati and Grosholz 2009). In a study examining the influence of Spartina marshes and detritus availability on the spatial structure and temporal variability of macrobenthic associations, Netto and Lana (1999) suggested that spatial and temporal shifts among infaunal organisms may be more evident than those of mobile epibenthic forms.

Our study area contained no 2-cm-diameter burrows among Spartina patches, which indicates the absence of large decapod crustaceans; we also observed a higher density of Annelida than Mollusca organisms. Spartina patches appeared to facilitate the colonization of oligochaetes at higher elevations, while also inhibiting taxa such as crustaceans and bivalves. However, macrofauna biomass did not differ significantly between habitats with and without Spartina. This result is consistent with the findings of a study on the effects of Spartina invasion on benthic macrofaunal assemblages in an Australian salt marsh (Cutajar et al. 2012), but not with those of previous studies that found a negative correlation between root biomass and macrofaunal biomass (Forbes and Lopez 1990, Wang et al. 2010). 
Our CCA results clearly showed that Spartina invasion was a key factor in macrofaunal distribution (Fig. 6). When belowground biomass was sufficient, macrofauna diversity, density, and richness decreased to a greater extent among Spartina patches, whereas a few species, such as epifauna, remained dominant. Macrofauna species may have been depleted compared to both native marsh and bare mudflats due to the belowground biomass of roots and rhizomes. Our CCA results also indicated that organic matter content, salinity, and pH can be considered as crucial factors for community organization. Benthic deposit feeders assimilate resuspended benthic diatoms from bulk particulate organic matter (Kang et al. 2003; Kanaya et al. 2008). Despite the high salinity tolerance of $S$. densiflora, its growth is limited under halosaline conditions; we found that salinity was positively related to belowground $S$. anglica biomass. Lee et al. (2016) demonstrated the high invasion potential of hybrid Spartina genotypes due to their strong salinity tolerance; plants under high salinity conditions had a significantly greater root to shoot biomass ratio than those under either low or medium salinity conditions. Interactions between $\mathrm{pH}$ and salinity are important for evaluating Spartina responses in nutrient culture and salt marsh experiments (Linthurst et al. 1981).

In conclusion, we investigated the effects of $S$. anglica patch size in a range of tidal flat marsh habitats, to understand its reproductive strategies throughout the invasion process and its influence on macrobenthic communities. Smaller Spartina patches, which indicate a shorter invasion history (1-2 years), allocated more resources to rhizomes than larger patches, to adapt to the harsh tidal environment. Spartina invasion reduced macrofaunal species richness, diversity, and density, but may have enhanced epifauna in the tidal flat marsh. Macrofaunal assemblages may have been negatively impacted in habitats under Spartina invasion; however, the results differed among habitat types. This study focused on early invasion Spartina patches rather than established meadows, to understand its initial asexual reproductive strategies and effects on macrofauna. Our results indicate that rhizomes in early $S$. anglica patches represent an important means of population expansion from favorable to unfavorable environments. Early detection and a rapid response are key for managing Spartina invasion, particularly within 5 years, when $S$. anglica invasion has a major negative impact on native microbenthic communities. Further studies should perform long-term ( $>5$ years) monitoring of Spartina invasion patterns and structural characteristics, and assess the impact on surrounding macrobenthic communities.

\section{Declarations}

\section{$\diamond$ Funding}

This work was supported by the Korea Environment Industry and Technology Institute (KEITI) through the Urban Ecological Health Promotion Technology Development Project, funded by the Korea Ministry of Environment (MOE) (no. 2020002770002). This work was also supported by the National Research Foundation of Korea (NRF) grant funded by the Korean government (MSIT) (2018R1C1B6005351). This research was also partially supported by the Hyundai Motor Chung Mong-Koo Foundation. 


\section{$\checkmark$ Conflicts of interest/Competing interests}

The authors declare no conflict of interests nor competing interests.

\section{$\checkmark$ Availability of data and material}

All data produced in this study are available upon requests from the corresponding author.

\section{$\checkmark$ Code availability}

'Not applicable' for that section.

\section{$\checkmark$ Ethics approval}

Sampling protocols were established in compliance with the ethical standards.

\section{$\checkmark$ Consent to participate}

All persons entitled to authorship have been so named and have agreed to participate.

\section{$\checkmark$ Consent for publication}

All authors have seen and agreed to the submitted version of the manuscript.

\section{$\checkmark$ Acknowledgments}

This work was supported by the Korea Environment Industry and Technology Institute (KEITI) through the Urban Ecological Health Promotion Technology Development Project, funded by the Korea Ministry of Environment (MOE) (no. 2020002770002). This work was also supported by the National Research Foundation of Korea (NRF) grant funded by the Korean government (MSIT) (2018R1C1B6005351). This research was also partially supported by the Hyundai Motor Chung Mong-Koo Foundation.

\section{References}

1. Amsberry L, Baker MA, Ewanchuk PJ, Bertness MD (2000) Clonal integration and the expansion of Phragmites australis. Ecol Appl 10:1110-1118. doi:10.1890/1051-

0761(2000)010[1110:CIATEO]2.0.CO;2 
2. Ayres DR, Strong DR (2002) The Spartina invasion of San Francisco Bay. Aquatic Nuisance Species Digest 4:37-39.

3. Barbier EB, Hacker SD, Kennedy C, Koch EW, Stier AC, Silliman BR (2011) The value of estuarine and coastal ecosystem services. Ecol Monogr 81:169-193. doi:10.1890/10-1510.1

4. Baumel A, Ainouche M, Kalendar R, Schulman AH (2002) Retrotransposons and genomic stability in populations of the young allopolyploid species Spartina anglica C.E. Hubbard (Poaceae). Mol Biol Evol 19:1218-1227. doi:10.1093/oxfordjournals.molbev.a004182

5. Boorman LA (1999) Salt marshes: Present functioning and future change. Mangroves and Salt Marshes 3:227-241. doi:10.1023/A:1009998812838

6. Bouma TJ, Ortells V, Ysebaert T (2009) Comparing biodiversity effects among ecosystem engineers of contrasting strength: Macrofauna diversity in Zostera noltii and Spartina anglica vegetation. Helgol Mar Res 63:3-18. doi:10.1007/s10152-008-0133-8

7. Bouma TJ, De Vries MB, Herman PM (2010) Comparing ecosystem engineering efficiency of two plant species with contrasting growth strategies. Ecology 91:2696-2704. doi:org/10.1890/09-0690.1

8. Bray RH, Kurtz LT (1945) Determination of total, organic, and available forms of phosphorus in soils. Soil Sci 59:39-46. doi:10.1097/00010694-194501000-00006

9. Brusati ED, Grosholz ED (2006) Native and introduced ecosystem engineers produce contrasting effects on estuarine infaunal communities. Biol Invasions 8:683-695. doi:10.1007/s10530-0052889-y

10. Brusati ED, Grosholz ED (2009) Does invasion of hybrid cordgrass change estuarine food webs? Biol Invasions 11:917-926. doi:10.1007/s10530-008-9304-4

11. Castillo JM, Grewell BJ, Pickart AJ, Figueroa E, Sytsma M (2016) Variation in tussock architecture of the invasive cordgrass Spartina densiflora along the Pacific Coast of North America. Biol Invasions 18:2159-2174. doi:10.1007/s10530-015-0991-3

12. Chen H, Li B, Hu J, Chen J, Wu J (2007) Effects of Spartina alterniflora invasion on benthic nematode communities in the Yangtze Estuary. Mar Ecol Prog Ser 336:99-110. doi:10.3354/meps336099

13. Chen Z, Guo L, Jin B, Wu J, Zheng G (2009) Effect of the exotic plant Spartina alterniflora on macrobenthos communities in salt marshes of the Yangtze River Estuary, China. Estuar Coast Shelf S 82:265-272. doi:10.1016/j.ecss.2009.01.014

14. Chung $\mathrm{CH}$ (1993) Thirty years of ecological engineering with Spartina plantations in China. Ecol Eng 2:261-289. doi:10.1016/0925-8574(93)90019-C

15. Compton TJ, Holthuijsen S, Koolhaas A, Dekinga A, Horn TJ, Smith J, Galama Y, Brugge M, Wal DVD, Meer J, Veer HW, Piersma T (2013) Distinctly variable mudscapes: Distribution gradients of intertidal macrofauna across the Dutch Wadden Sea. J Sea Res 82:103-116.

doi:10.1016/j.seares.2013.02.002

16. Costa CSB, Marangoni JC, Azevedo AMG (2003) Plant zonation in irregularly flooded salt marshes: Relative importance of stress tolerance and biological interactions. J Ecol 91:951-965. doi:10.1046/j.1365-2745.2003.00821.x 
17. Costanza R, d'Arge R, de Groot R, Farber S, Grasso M, Hannon B, Limburg K, Naeem S, O'Neill RV, Paruelo J, Raskin RG, Sutton P, van den Belt M (1997) The value of the world's ecosystem services and natural capital. Nature 387:253-260. doi:10.1038/387253a0

18. Curado G, Sanchez-Moyano JE, Figueroa E, Castillo JM (2014) Do Spartina maritima plantations enhance the macroinvertebrate community in European salt marshes? Estuar Coast 37:589-601. doi:10.1007/s12237-013-9713-1

19. Cutajar J, Shimeta J, Nugegoda D (2012) Impacts of the invasive grass Spartina anglica on benthic macrofaunal assemblages in a temperate Australian saltmarsh. Mar Ecol Prog Ser. doi:10.3354/meps09826

20. Daehler CC, Strong DR (1996) Status, prediction and prevention of introduced cordgrass Spartina spp. invasions in Pacific estuaries, USA. Biol Conserv 78:1-2. doi:10.1016/0006-3207(96)00017-1

21. Dame RF, Kenny PD (1986) Variability of Spartina alterniflora primary production in the euhaline North Inlet estuary. Mar Ecol Prog Ser 32:71-80. doi:10.3354/MEPS032071

22. Darby FA, Turner RE (2008) Below- and aboveground Spartina alterniflora production in a Louisiana salt marsh. Estuaries and Coasts 31:223-231. doi:10.1007/s12237-007-9014-7

23. Ellison AM, Bertness MD, Miller T (1986) Seasonal patterns in the belowground biomass of Spartina alterniflora (Gramineae) across a tidal gradient. Am J Bot 73:1548-1554. doi:10.1002/j.15372197.1986.tb10905.x

24. Forbes TL, Lopez GR (1990) The effect of food concentration, body size, and environmental oxygen tension on the growth of the deposit-feeding polycheate, Capitella species 1. Limnol Oceanogr 35:1535-1544. doi:10.4319/lo.1990.35.7.1535

25. Ganju NK, Kirwan ML, Dickhudt PJ, Guntenspergen GR, Cahoon DR, Kroeger KD (2015) Sediment transport-based metrics of wetland stability. Geophysical Research Letters 42:7992-8000. doi:10.1002/2015GL065980

26. Ge BM, Bao YX, Cheng HY, Zhang DZ, Hu ZY (2012) Influence of Spartina alterniflora invasion stages on macrobenthic communities on a tidal flat in Wenzhou Bay, China. Braz J Oceanogr 60:441-448. doi:10.1590/S1679-87592012000300014

27. Gray AJ, Marshall DF, Raybould AF (1991) A century of evolution in Spartina anglica. Adv Ecol Res 21:1-62. doi:10.1016/S0065-2504(08)60096-3

28. Grosholz ED, Levin LA, Tyler AC, Neira C (2009) Changes in community structure and ecosystem function following Spartina alterniflora invasion of Pacific estuaries. In: Silliman BR, Bertness M, Grosholz E (eds) Human Impacts on Salt Marshes: A Global Perspective. Berkeley, CA: University of California Press, pp. 23-40.

29. Hacker SD, Heimer D, Hellquist CE, Reeder TG, Reeves B, Riordan TJ, Dethier MN (2001) A marine plant (Spartina anglica) invades widely varying habitats: Potential mechanisms of invasion and control. Biol Invasions 3:211-217. doi:10.1023/A:1014555516373

30. Hazelton EL, Mozdzer TJ, Burdick DM, Kettenring KM, Whigham DF (2014) Phragmites australis management in the United States: 40 years of methods and outcomes. AoB Plants 


\section{6. doi:10.1093/aobpla/plu001}

31. Hedge P, Kriwoken LK (2000) Evidence for effects of Spartina anglica invasion on benthic macrofauna in Little Swanport estuary, Tasmania. Austral Ecol 25:150-159. doi:10.1046/j.14429993.2000.01016.x

32. Hedge P, Kriwoken LK, Patten K (2003) A review of Spartina management in Washington State, US. J Aquat Plant Manag 41:82-90.

33. Hosack GR, Dumbauld BR, Ruesink JL, Armstrong DA (2006) Habitat associations of estuarine species: Comparisons of intertidal mudflat, seagrass (Zostera marina), and oyster (Crassostrea gigas) habitats. Estuaries and Coasts 29:1150-1160. doi:10.1007/BF02781816

34. Hubbard JCE, Stebbings RE (1968) Spartina marshes in Southern England: VII. Stratigraphy of the Keysworth marsh, Poole Harbour. J Ecol 56:707-722. doi:10.2307/2258102

35. Hubbard JCE, Partridge TR (1981) Tidal immersion and the growth of Spartina anglica marshes in the Waihopai River Estuary, New Zealand. NZ J Bot 19:5-121. doi:10.1080/0028825X.1981.10425195

36. Kanaya G, Takagi S, Kikuchi E (2008) Dietary contribution of the microphytobenthos to infaunal deposit feeders in an estuarine mudflat in Japan. Mar Biol 155:543-553. doi:10.1007/s00227-0081053-5

37. Kang CK, Kim JB, Lee KS, Kim JB, Lee PY, Hong JS (2003) Trophic importance of benthic microalgae to macrozoobenthos in coastal bay systems in Korea: Dual stable $\mathrm{C}$ and $\mathrm{N}$ isotope analyses. Mar Ecol Prog Ser 259:79-92. doi:10.3354/meps259079

38. Kim S, Hong JS, Kim DW (2019) Effective initiation diffusion model based on data of patches growing in smooth cordgrass Spartina alterniflora. The Fourth Asian Mar Biol Symposium. Taiwan.

39. Kimura T, Hanai T, Kimura S, Fujioka E (2016) Identification of invasive alien species Spartina alterniflora in Japan using morphological characteristics as compared with native species Phragmites australis. Japanese Journal of Benthology 70:91-94. (In Japanese with English summary)

40. Kriwoken LK, Hedge P (2000) Exotic species and estuaries: Managing Spartina anglica in Tasmania, Australia. Ocean Coast Manag 43:573-584. doi:10.1016/S0964-5691(00)00047-8

41. Lee AK, Ayres DR, Pakenham-Walsh MR, Strong DR (2016) Responses to salinity of Spartina hybrids formed in San Francisco Bay, California (S. alterniflora $\times$ foliosa and S. densiflora $\times$ foliosa). Biol Invasions 18:2207-2219. doi:10.1007/s10530-015-1011-3

42. Levin LA, Neira C, Grosholz ED (2006) Invasive cordgrass modifies wetland trophic function. Ecology 87:419-432. doi:10.1890/04-1752

43. Linthurst RA, Blum U (1981) Growth modifications of Spartina alterniflora Loisel. by the interaction of $\mathrm{pH}$ and salinity under controlled conditions. J Exp Mar Biol Ecol 55:207-218. doi:10.1016/00220981(81)90112-X

44. Lodge DM (1993) Biol Invasions: Lessons for ecology. Trends Ecol Evol 8:133-137. doi:10.1016/0169-5347(93)90025-K 
45. Moller I, Kudella M, Rupprecht F, Spencer T, Paul M, van Wesenbeeck BK, Wolters G, Jensen K, Bouma, TJ, Miranda-Lange M, Schimmels S (2014) Wave attenuation over coastal salt marshes under storm surge conditions. Nat Geosci 7:727-731. doi:10.1038/NGE02287

46. Morris JT, Sundareshwar PV, Nietch CT, Kjerfve B, Cahoon DR (2002) Responses of coastal wetlands to rising sea level. Ecology 83:2869-2877. doi:10.1890/00129658(2002)083[2869:ROCWTR]2.0.C0;2

47. Murphy J, Riley JP (1962) A modified single solution method for the determination of phosphate in natural waters. Anal Chim Acta 27:31-36. doi:10.1016/S0003-2670(00)88444-5

48. Neira C, Grosholz ED, Levin LA, Blake R (2006). Mechanisms generating modification of benthos following tidal flat invasion by a Spartina hybrid. Ecol Appl 16:1391-1404. doi:10.1890/10510761(2006)016[1391:MGMOBF]2.0.C0;2

49. Neira C, Levin LA, Grosholz ED (2005) Benthic macrofaunal communities of three sites in San Francisco Bay invaded by hybrid Spartina, with comparison to uninvaded habitats. Mar Ecol Prog Ser 292:111-126. doi:10.3354/MEPS292111

50. Neira C, Levin LA, Grosholz ED, Mendoza G (2007) Influence of invasive Spartina growth stages on associated macrofaunal communities. Biol Invasions 9:975-993. doi:10.1007/s10530-007-9097-x

51. Netto SA, Lana PC (1997) Influence of Spartina alterniflora on superficial sediment characteristics of tidal flats in Paranagua Bay (southeastern Brazil). Estuar Coast Shelf Sci 44:641-648. doi:10.1006/ecss.1996.0154

52. Netto SA, Lana PC (1999) The role of above- and below-ground components of Spartina alterniflora (Loisel) and detritus biomass in structuring macrobenthic associations of Paranagua Bay (SE, Brazil). Hydrobiologia 400:167-177. doi:10.1023/A:1003753001411

53. Petrone RM, Waddington JM, Price JS (2001) Ecosystem scale evapotranspiration and net $\mathrm{CO}_{2}$ exchange from a restored peatland. Hydrological Processes 15:2839-2845. doi:10.1002/hyp.475

54. Pielou EC (1966) The measurement of diversity in different types of biological collections. J Theor Biol 13:131-144. doi:10.1016/0022-5193(66)90013-0

55. Prieur-Richard AH, Lavorel S, Grigulis K, Dos Santos A (2000) Plant community diversity and invasibility by exotics: Invasion of Mediterranean old fields by Conyza bonariensis and Conyza canadensis. Ecol Lett 3:412-422. doi:10.1046/j.1461-0248.2000.00157.x

56. Quan W, Zhang H, Wu Z, Jin S, Tang F, Dong J (2016) Does invasion of Spartina alterniflora alter microhabitats and benthic communities of salt marshes in Yangtze River estuary? Ecol Eng 88:153164. doi:10.1016/j.ecoleng.2015.12.026

57. Raybould AF, Gray AJ, Lawrence MJ, Marshall DF (1991) The evolution of Spartina anglica C.E. Hubbard (Gramineae): Origin and genetic variability. Biol J Linn Soc 43:111-126. doi:10.1111/j.1095-8312.1991.tb00588.x

58. Schirmel J, Bundschuh M, Entling MH, et al. (2016) Impacts of invasive plants on resident animals across ecosystems, taxa, and feeding types: A global assessment. Glob Chang Biol 22:594-603. doi:10.1111/gcb.13093 
59. Schubauer JP, Hopkinson CS (1984) Above- and belowground emergent macrophyte production and turnover in a coastal marsh ecosystem, Georgia. Limnol Oceanogr 29:1052-1065. doi:10.4319/lo.1984.29.5.1052

60. Sheehan MR, Ellison JC (2014) Intertidal morphology change following Spartina anglica introduction, Tamar Estuary, Tasmania. Estuar Coast Shelf Sci 149:24-37. doi:10.1016/j.ecss.2014.07.006

61. Snelgrove PVR (1998) The biodiversity of macrofaunal organisms in marine sediments. Biodivers Conserv 7:1123-1132. doi:10.1023/A:1008867313340

62. Solorzano $L$ (1969) Determination of ammonia in natural waters by the phenolhypochlorite method 1. Limnol Oceanogr 14:799-801. doi:10.4319/lo.1969.14.5.0799

63. Tang M, Kristensen E (2010) Associations between macrobenthos and invasive cordgrass, Spartina anglica, in the Danish Wadden Sea. Helgol Mar Res 64:321-329. doi:10.1007/s10152-009-0187-2

64. Temmerman S, Govers G, Wartel S, Meire P (2004) Modelling estuarine variations in tidal marsh sedimentation: Response to changing sea level and suspended sediment concentrations. Mar Geol 212:1-19. doi:10.1016/j.margeo.2004.10.021

65. Tripathee R, Schafer KVR (2015) Above- and belowground biomass allocation in four dominant salt marsh species of the eastern United States. Wetlands 35:21-30. doi:10.1007/s13157-014-0589-z

66. Wang R, Yuan L, Zhang L. (2010) Impacts of Spartina alterniflora invasion on the benthic communities of salt marshes in the Yangtze Estuary, China. Ecol Eng 36:799-806. doi:10.1016/j.ecoleng.2010.02.005

67. Worm B, Barbier EB, Beaumont N, Duffy JE, Folke C, Halpern B, Jackson J, Lotze H, Micheli F, Palumbi S, Sala E, Selkoe K, Stachowicz J, Watson R (2003) Impacts of biodiversity loss on ocean ecosystem services. Science, 314:787-790. doi:10.1126/science.1132294

68. Wu YT, Wang CH, Zhang XD, et al. (2009) Effects of saltmarsh invasion by Spartina alterniflora on arthropod community structure and diets. Biol Invasions 11:635-649. doi:10.1007/s10530-0089279-1

69. Xiao Y, Tang J, Qing H, Ouyang Y, Zhao Y, Zhou C, An S (2010) Clonal integration enhances flood tolerance of Spartina alterniflora daughter ramets. Aquat Bot 92:9-13. doi:10.1016/j.aquabot.2009.09.001

70. Zou FS, Song XJ, Chen W, Zheng XR, Chen JH (1999) The diversity of benthic macrofauna on mud flat in Dongzhaigang Mangrove Reserve, Hainan. Chinese Biodiversity 7:175. doi:10.17520/biods. 1999027

71. Zuo P, Zhao S, Liu C, Wang C, Liang Y (2012) Distribution of Spartina spp. along China's coast. Ecol Eng 40:160-166. doi:10.1016/j.ecoleng.2011.12.014

\section{Figures}




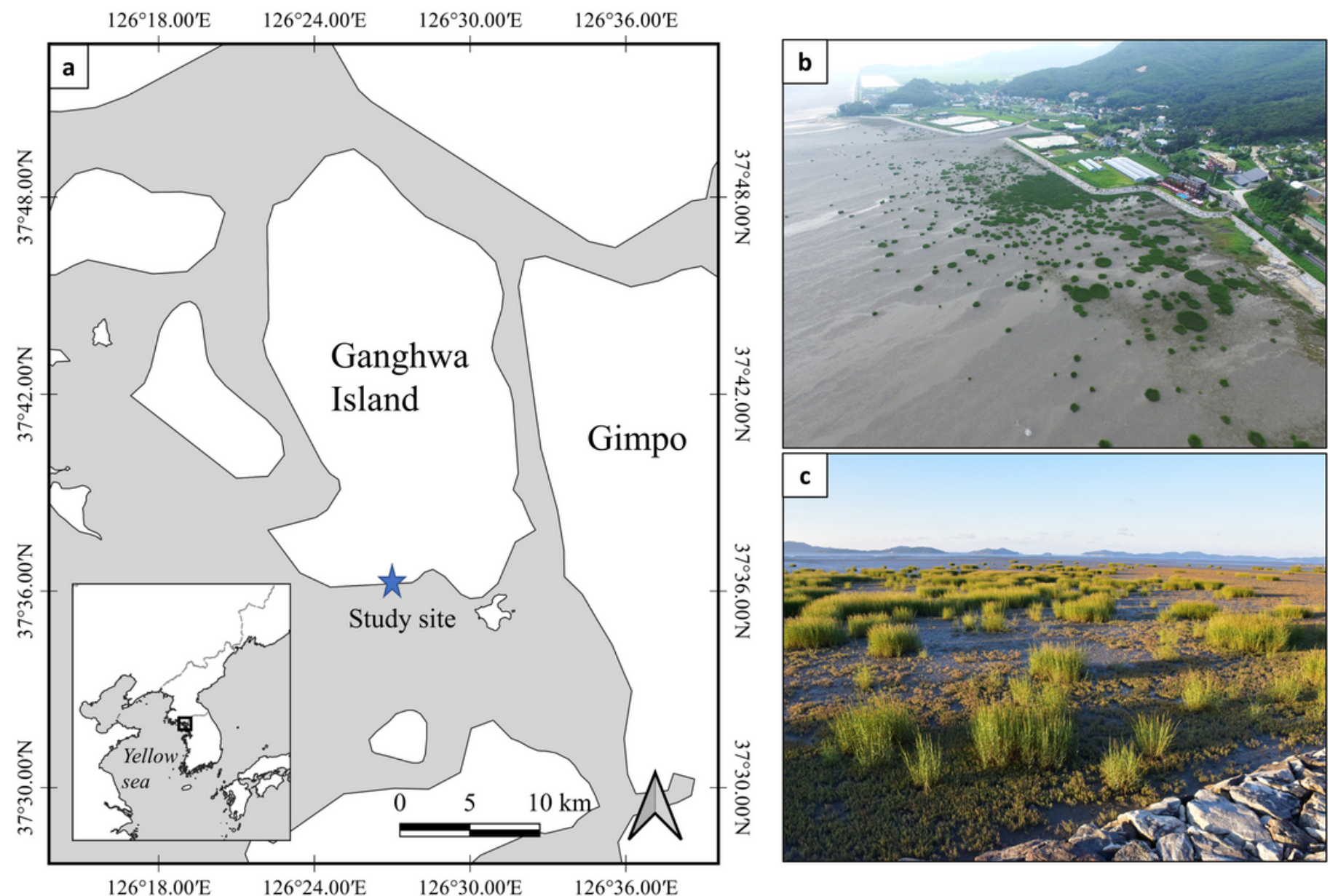

Figure 1

(a) The study site at Dongmak-ri, Ganghwa Island, South Korea. (b) Aerial image of Spartina anglica meadow and patches captured a by drone (height, 150 m; September 6, 2016). (c) S. anglica patches within Suaeda japonica vegetation (October 9, 2016). 


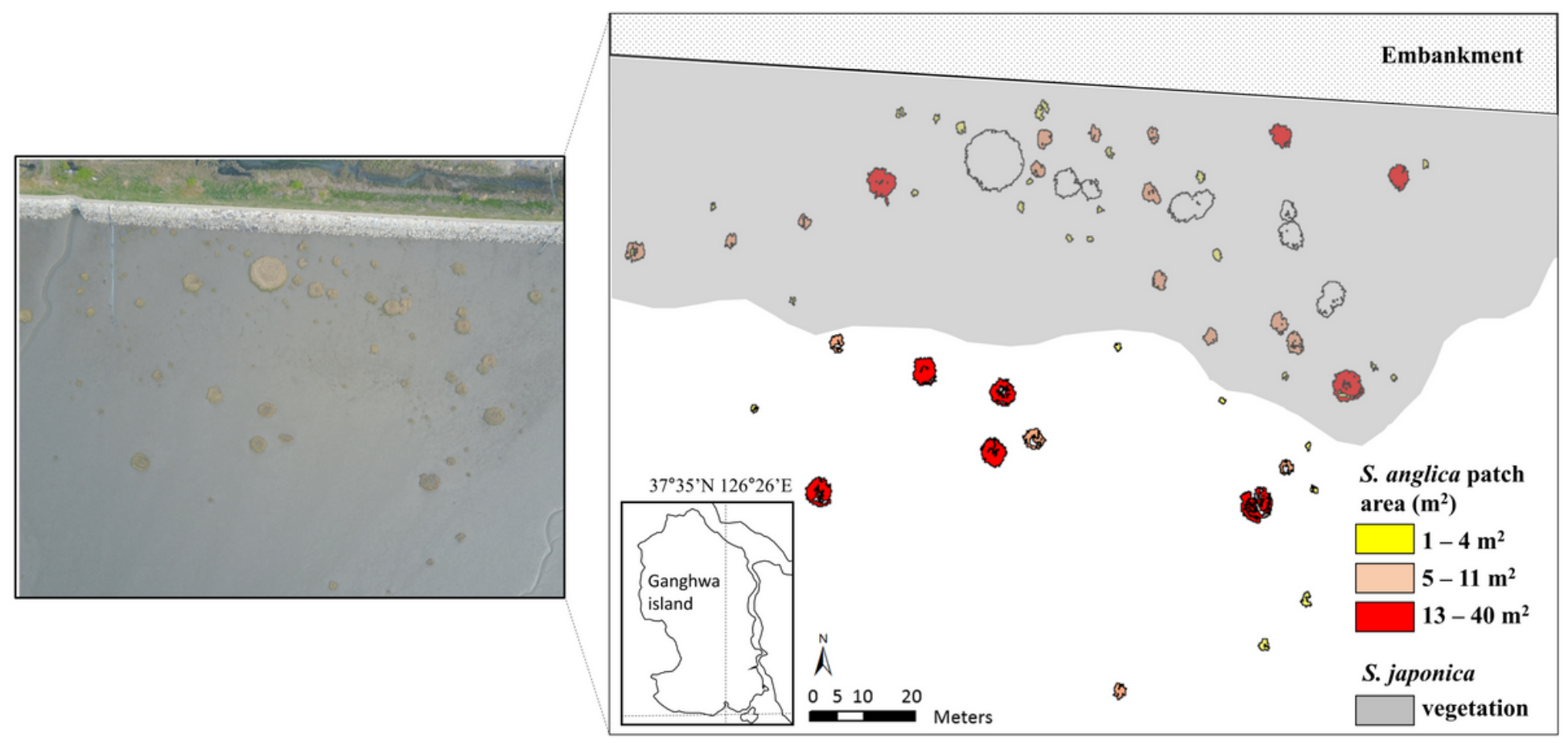

\section{Figure 2}

Spartina anglica patches at the study area in Dongmak-ri, Ganghwa Island, South Korea. Colors indicate patch sizes on bare mudflats. Grey shading indicates Suaeda japonica vegetation. Macrobenthic sampling 

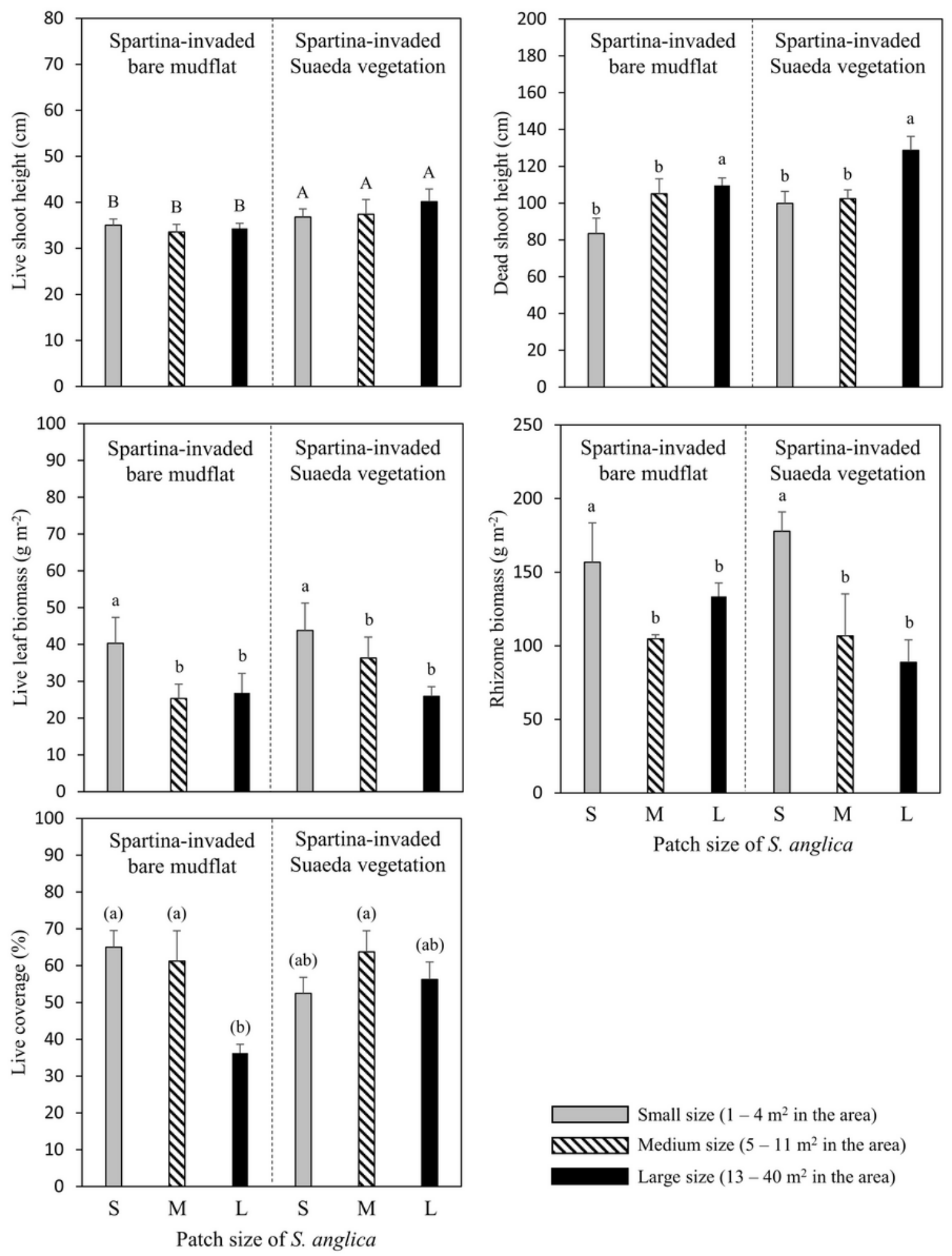

Small size ( $1-4 \mathrm{~m}^{2}$ in the area)

DIDV Medium size $\left(5-11 \mathrm{~m}^{2}\right.$ in the area)

Large size $\left(13-40 \mathrm{~m}^{2}\right.$ in the area)

Figure 3

Relationships between living and dead Spartina anglica biomass and patch size for Suaeda japonica vegetation, and for bare mudflats in Donggeom-ri, Ganghwa Island, South Korea. Error bars indicate standard error of the mean (SEM). Different letters indicate significant differences between habitats (capital letters) or among S. anglica patch sizes (small letters) according to two-way analysis of variance 
(ANOVA) and Tukey's honestly significant difference (HSD) test or the Kruskal-Wallis test $(P<0.05, n=$ 4),. Brackets indicate an interaction between patch size and habitat.

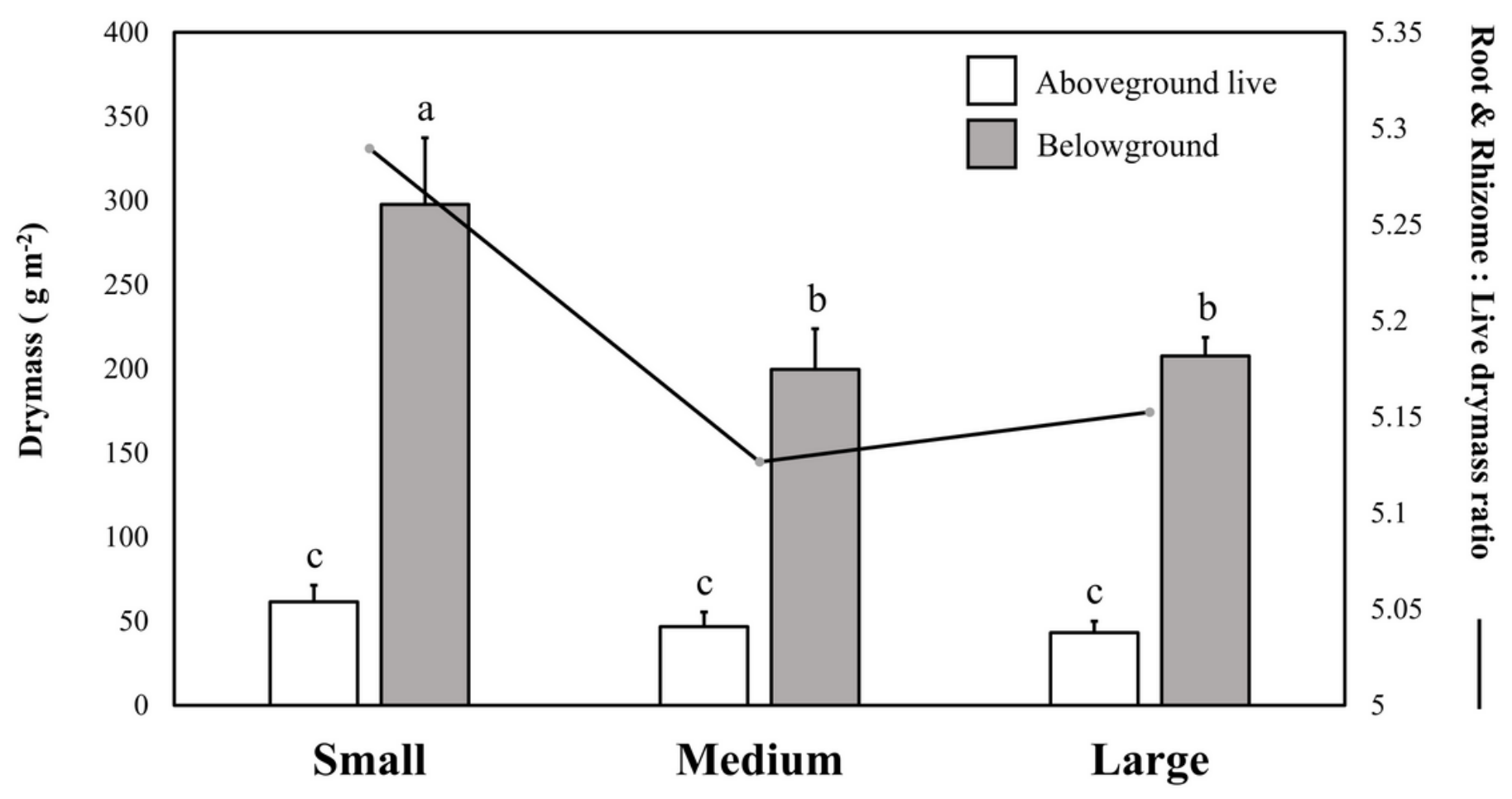

Figure 4

Variation in above- and below-ground biomass, and their ratio, by S. anglica patch size. Error bars indicate SEM. Different letters indicate significant differences according to one-way ANOVA and Tukey's HSD test $(P<0.05, n=8)$. 

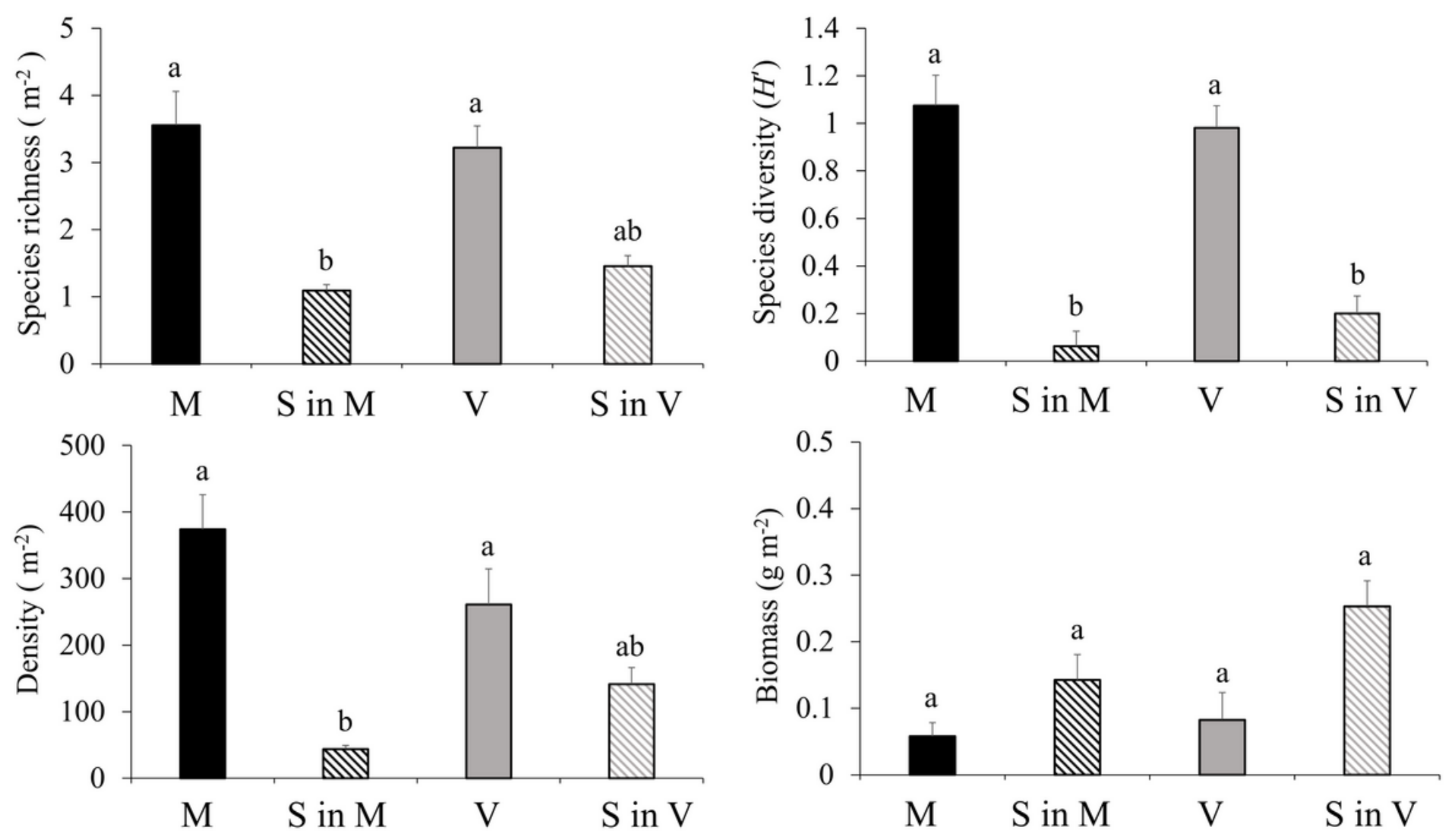

Figure 5

Mean species richness, species diversity $\left(\mathrm{H}^{\prime}\right)$, species density, and biomass of total macrofauna for samples in four habitats: bare mudflats $(M)$, Spartina-invaded bare mudflats ( $S$ in $M)$, Suaeda vegetation $(V)$, and Spartina-invaded Suaeda vegetation ( $S$ in V). Error bars indicate SEM ( $n=9$ for $M, V ; n=12$ for $S$ in $M, S$ in $V$ ). Different letters indicate significant differences among habitats according to one-way ANOVA and Tukey's HSD test $(P<0.05)$. 


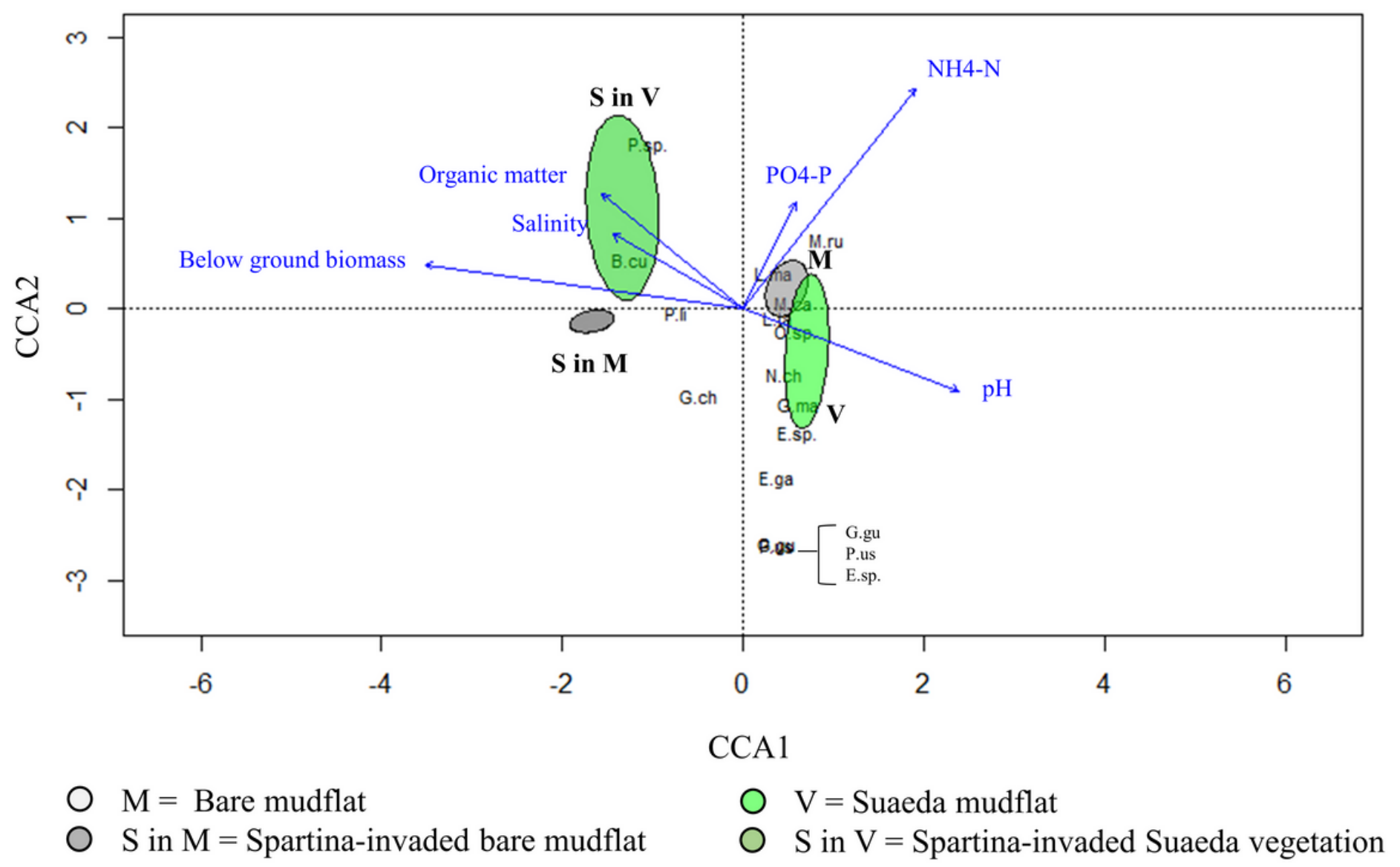

Figure 6

Canonical correspondence analysis (CCA) ordination of four macrofaunal assemblages and six environmental variables from the sampling site at Dongmak-ri, Ganghwa Island ( $n=9$ for $M, V ; n=12$ for $M$ with $S$, and $V$ with S). Zonation was determined according to the standard error (SE). E.sp, Eteone sp.; G.ma, Glycera macintoshi G.gu, Glycinde gurjanovae; M.ca, Mediomastus californiensis; N.ch, Nephtys chemulpoensis; O.sp., oligochaeta sp.; P.us, Paraleonnates uschakovi; P.li, Perinereis linea; B.cu, Batillaria cumingi; E.ga, Estellacar galactodes; G.ch, Glauconome chinensis; L.ta, Lactiforis takii; L.ma, Laternula marilina; M.ru, Moerella rutile; P.sp., Potamocorbula sp.

\section{Supplementary Files}

This is a list of supplementary files associated with this preprint. Click to download.

- SupplementaryMaterials.docx 